\title{
Characteristics of Diurnal and Seasonal Cycles in Global Monsoon Systems
}

\author{
William K. M. LAU \\ Laboratory for Atmospheres, NASA / Goddard Space Flight Center, Greenbelt, MD 20771, USA \\ Kyu-Myong KIM, and Myong-In LEE
}

Goddard Earth Sciences and Technology Center, UMBC, Baltimore, Maryland, USA

(Manuscript received 23 December 2005, in final form 24 November 2006)

\begin{abstract}
In this paper, we characterize the climatological diurnal cycles over monsoon land and ocean regions, and seasonal cycles for six major monsoon systems around the world, from observations and outputs of the NASA Seasonal-to-Interannual Prediction Project (NSIPP) general circulation model outputs. Over monsoon land regions, the diurnal cycle has a pronounced late afternoon peak in rainfall and over the oceans a much weak diurnal signal with an early morning peak. The NSIPP model produces a daily peak in rainfall about 2-3 hours earlier than observed, possibly attributed to a cumulus parameterization which does not include cloud life cycle effects, and which lack detailed treatment of boundary layer processes. The seasonal cycles of all monsoon rain systems are controlled by an ITCZ and a subtropical and/or extratropical component due to the presence of contiguous large continental land mass. Strong climatological intraseasonal oscillations (CISO) are found in the monsoon systems of South Asia and East Asia, Australia, and South America, and to a lesser degree for West Africa and Mexico/North America. The NSIPP model captures the slow component seasonal component reasonably well, but the CISO's are not well simulated.

Analysis with reference to a new monsoon index shows that the major monsoon systems can be classified into three major groups (M1-3) according to the relative strength of continental vs. oceanic controls. East Asian and South Asian monsoons belong to a group (M1), where the continental influence is stronger than that from the ITCZ. The North America and South America monsoons show similar characteristics with the ITCZ influence slight stronger than continental influence (M2). The West Africa and Australia monsoons are found to be essentially ITCZ-monsoon systems (M3), with strong oceanic control, and limited poleward excursion of the monsoon rainbelt. We also find a clear trend associated with an increase in continentality for M3 monsoons, i.e., the West African and the Australian monsoons in the last two decades. We speculate that the former is linked to the partially recovery of the Sahel drought since the 1980's.
\end{abstract}

\section{Introduction}

The Coordinated Enhanced Observing Period (CEOP) is an element of the World Climate Re-

Corresponding Author: William K. M. Lau, Laboratory for Atmospheres, NASA/Goddard Space Flight Center, Greenbelt, MD 20771, USA. Email: lau@climate.gsfc.nasa.gov

(C) 2007, Meteorological Society of Japan search Programme (WCRP) initiated by Global Energy and Water Cycle Experiment (GEWEX) in 2001 as a first step toward establishing an integrated observation and modeling system for studies of the global water cycle. CEOP encompasses a comprehensive set of observations from reference sites, satellite missions, and data assimilation systems, with requirements driven by two major science thrusts, i.e., Water 
and Energy Balance Studies (WEBS), and CEOP Inter-Monsoon Studies (CIMS) (Leese 2001). The main objectives of CIMS are to: a) provide better understanding of fundamental physical processes, i.e., diurnal cycle, annual cycle, intraseasonal oscillation, in monsoon regions around the world, and b) demonstrate the synergy and utility of CEOP data in providing a pathway for model physics evaluation and improvement.

Phase-I of CEOP (2003-2005) was mainly devoted to data collection, processing, and quality control, as well as pilot projects demonstrating the use and application of CEOP data for water cycle studies. As the data collection phase is being completed, and the research phase begins in 2005, two full annual cycles (2003-2004) of research-quality data sets from satellites, reference sites, and model output location time series (MOLTS) have been processed and made available to the scientific community for pilot studies (Roads et al. 2003; Lau et al. 2004; Matsumoto and Takahara 2005). This article presents results aimed at the intercomparison of the diurnal and seasonal variations of all major monsoon systems around the world. It serves as a demonstration of the CIMS approach in providing new insights into characterizing and understanding monsoon systems, and identifying new pathways for model physics improvement.

Previous studies have shown that the diurnal cycles of precipitation over tropical land and oceans are very complex, depending not only on convective radiative energy balance, but also local topographic effects, land-sea breeze, interaction with neighboring cloud systems, and influence from propagating features (Sorooshian et al. 2002; Yang and Slingo 2001). Since an objective here is to evaluate performance of AGCMs which currently are incapable of simulating the detailed features of diurnal cycles of various rain systems, we shall focus on features of the climatological diurnal cycle, which are relevant to the intrinsic onedimensional convective energy balance between precipitation and surface heating. This energy balance will have the most contrast between continental land mass and the ocean. Therefore for the diurnal cycle intercomparison, we focus on the contrasts of the diurnal cycles between land, ocean and coastal domain in monsoon re- gions. Much higher spatial resolution data and models are required to resolve local and transient features, which are not covered in this paper. For the seasonal cycle, monsoon regions exhibit similar or different variations depending on the geography of the land-sea distribution. Details of seasonal cycle of individual regional monsoons have been reported in many previous studies (e.g., Ding and Sikka 2006; Lau et al. 2001; Manton and McBride 1992; Janicot and Sultan 2001; Gu and Adler 2004; Higgins et al. 1997; Zhou and Lau 1998; Marengo et al. 2001). The present work differs from previous studies in that we focus not on one monsoon system, but rather on the intercomparison of six major monsoon systems in the world, i.e., the East Asian Monsoon (EAM), the Indian Monsoon (IM), the Australian Monsoon (AUM), the West Africa Monsoon (WAM), the North America/Mexican Monsoon System (NAMS), and the South American Monsoon System (SAMS).

\section{Data description and approach}

We use 7 years (1998-2004) of TRMM TMI data to define the climatological diurnal cycles of tropical rainfall over the monsoon land and adjacent oceanic regions. The diurnal cycles are estimated based on the $35^{\circ}$ inclined orbit of the TRMM satellite, which allows rainfall measurements at equator to be sampled at twice daily at slightly different hours of day, which shift through the full diurnal cycle in approximately 47 days (Negri et al. 2002). We compare the diurnal cycle estimate from TRMM with simulations from the NASA Seasonal-to-Interannual Prediction Project (NSIPP) atmospheric general circulation model (AGCM). The NSIPP GCM is a gridpoint model based on the dynamical core of Suarez and Takacs (1995). The vertical coordinate is the standard sigma coordinate with 34 uneven vertical levels. NSIPP uses the Relaxed Arakawa-Schubert (RAS) scheme to parameterize convection (Moorthi and Suarez 1992). Large-scale cloudiness is determined using a relative humidity-based diagnostic scheme similar to Slingo (1987). The outputs used for the present analysis is obtained from a simulation has been performed with a uniform horizontal resolution of $2^{\circ} \times 2.5^{\circ}$ latitude-longitude with prescribed observed weekly sea surface temperature. Further detail de- 
scriptions of the model can be found in Bacmeister and Suarez (2002).

Additionally, pentad GPCP data with $2.5^{\circ} \times 2.5^{\circ}$ latitude-longitude grid are subdivided into different monsoon domains and used to depict the basic characteristics of monsoon climatological annual cycles, and to define a new index for characterizing the relative role of oceanic vs. continental land influence on monsoon systems. CEOP reference site data are used to highlight regional features and to crossvalidate the TRMM data, as well as intercompare with the NSIPP model and an ensemble of state-of-the-art coupled models used for Assessment Report 4 of the International Climate Change Panel (IPCC).

\section{Diurnal cycles}

The first part of the section recaptures the main features of the diurnal cycles of rainfall over land and ocean, which have been reported in a large number of previous studies (e.g., Asai et al. 1998; Dai 2001; Nesbitt and Zipser 2003; Meisner and Arkin 1987; Gray and Jackson 1977; Imaoka and Spencer 2000 and others). The second part is a demonstration of the regional differences comparing among TRMM, and CEOP reference site data and NSIPP model output. In addition, we present results using a new diagnostics which provide new information on the diurnal variation of the probability distribution function (PDF) of rain, thus moving a step closer in pinpointing sources of deficiency in model physics.

\section{a. Basic features}

The hours of maximum likelihood of rain have been computed over the entire tropics on a $2^{\circ} \times 2.5^{\circ}$ horizontal grid for June-JulyAugust, based on frequency distributions of TRMM rainfall data, as well as NSIPP model outputs. The NSIPP results shown are derived from 7-year, 1998-2004, model simulations which use prescribed observed weekly sea surface temperature. The spatial distributions of the hours of peak rainfall from observations and model are shown in Fig. 1. To eliminate sampling bias, the model results shown have been adjusted to the same sampling as seen from the TRMM orbit. In the following, time of day is defined as hour in local standard time (LST). Observations (Fig. 1, upper panel) shows

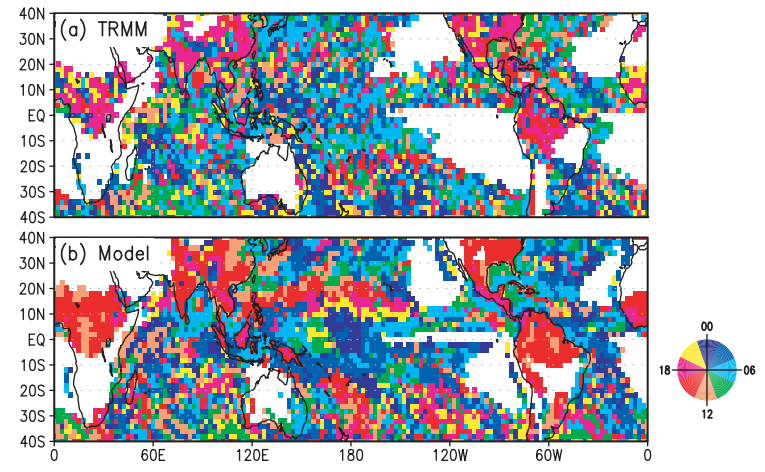

Fig. 1. Diurnal harmonic dial, showing the time of the day of maximum likelihood of rainfall for June-July-August, from (a) TRMM, and (b) NSIPP model.

that the most spatially coherent signals are found over the monsoon land regions of South and East Asia, West Africa, North America, and northwestern South America, with maximum rain occurring at around $18 \mathrm{hr}$. In contrast, over the open ocean, the maximum rain hour is around 06 hour. Over the oceanic rain zones, the ITCZ, maritime continent, and the vicinity of tropical islands, the distribution of phases of the diurnal cycles is very complex, indicating not only strong local effects, but also remote influences by topography and large scale circulation. The NSIPP model (Fig. 1a, lower panel) shows similar spatially coherent structures over the aforementioned tropical land regions, but the maximum rain occurs about 3 hours earlier than the TRMM observations. Over the ocean, the model shows stronger spatial coherence, with a rain maximum occurring earlier by about 3 hours compared to TRMM. Over the subtropical central Pacific, stretching from the Philippines to the Hawaii islands, a zone of continental-like diurnal signals (with mid-to-late afternoon peaks) can be seen in the NSIPP simulations. However, there is no observation counterpart to this feature. The reasons for the discrepancy are unknown, but may be due to spurious advection effects in the model. In December-January-February (not shown), the most pronounced coherent signals shift to the southern hemisphere land masses of Africa, northern and eastern Australia, and Brazil and the South Atlantic Convergence Zone (SACZ), with maximum occurring 


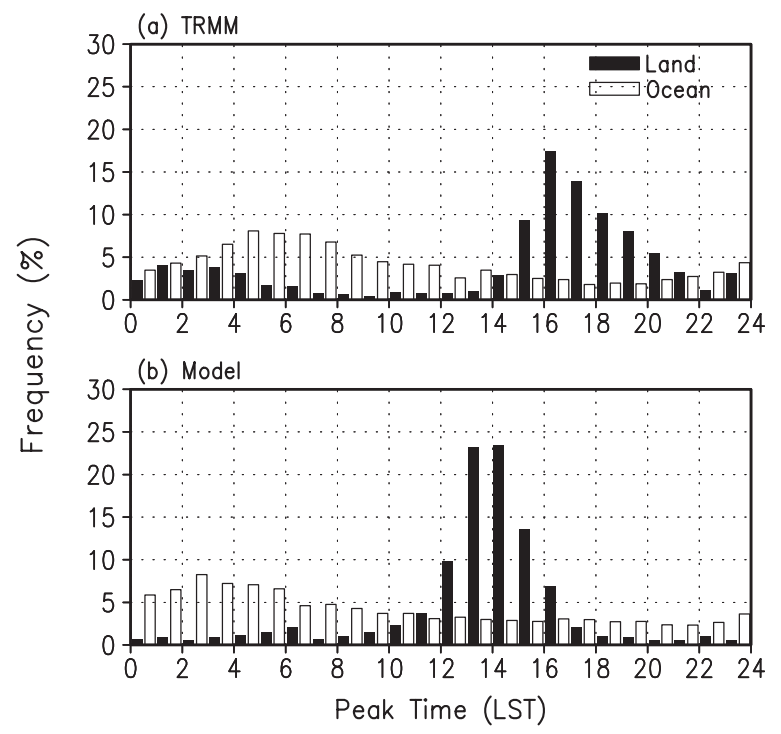

Fig. 2. Composite diurnal cycle in percentage of accumulated hourly rain to total daily rainfall for land (dark bar), and ocean (open bar) for (a) TRMM and (b) NSIPP model.

at around 18 hours. Similar to JJA, a distinct diurnal cycle with maximum at 06 hour is found over the ocean, but near islands and coastal regions the spatial pattern is very complex.

The contrasts between the land and ocean diurnal cycles from TRMM and NSIPP are clearly seen in the climatological hourly rainfall amount normalized to unit area and averaged, over all oceans and all land in the tropics (Fig. 2 ). Over land, the amplitude of the diurnal cycle is much stronger compared to that over ocean, showing clearly a late afternoon maximum ( 16 LST), with rainfall amount tapering off pass midnight, and a weak revival in early morning. Over ocean, the diurnal cycle is much weaker, as evidenced in the more uniform rainfall distribution throughout the day, with a broad maximum in early morning $(\sim 5-$ 7 LST). While the NSIPP GCM captures the aforementioned contrasts between the diurnal cycles of rainfall over land vs. ocean, it errs in producing maximum precipitation 3-4 hours too early over land and over oceans. The observed diurnal cycle over mixed land-ocean regions (not shown) in the tropics shows a strong semi-diurnal cycle, with a primary peak at 16-
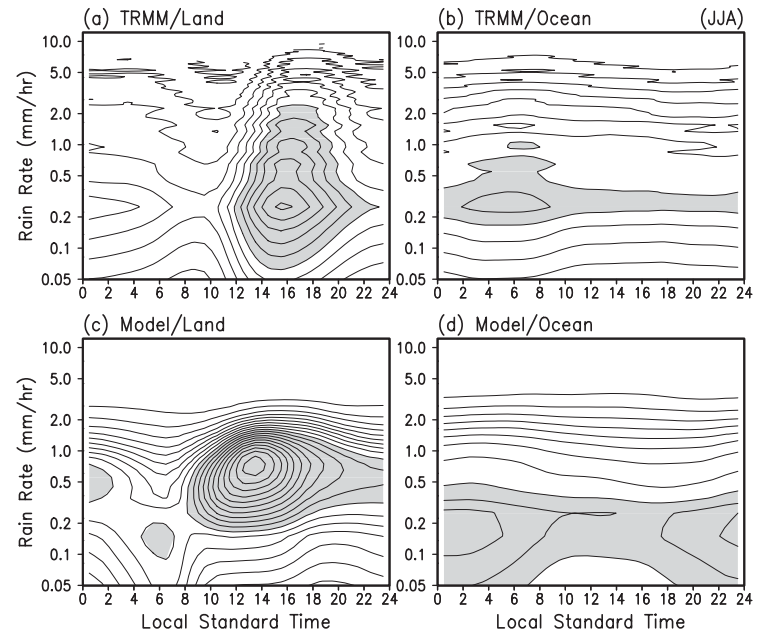

Fig. 3. Hourly rain-rate variations showing diurnal cycle of rainfall PDF for TRMM for (a) land and (b) ocean, and for NSIPP model for (b) land and (c) ocean. Units are non-dimensional, normalized to daily total amount per unit rain bin and per hour. Contour intervals are in $0.2 \times 10^{-4}$. Shading indicates value greater than $1.8 \times 10^{-4}$.

18 LST, and a secondary peak at 4-6 LST, showing the combined influence of land and oceanic processes. The NSIPP model also shows a double peak at 2-3 LST, and at 13-14 LST over mixed land-ocean regions, several hours earlier than the observed.

The contrasts in the diurnal cycle of rain between land vs. ocean, and observations vs. model are further highlighted by the shift in the rainfall probability distribution function (PDF) as a function of the hour of the day (Fig. 3). TRMM data show that over land (Fig. $3 a)$, moderate rain $\left(<0.2-0.5 \mathrm{~mm} \mathrm{hr}^{-1}\right)$ has the most contribution to the build-up phase, which begins around noon, and reaches the peak phase, at 16 LST. As the land convection system develops, the PDF widens with increased light $\left(<0.2 \mathrm{~mm} \mathrm{hr}^{-1}\right)$ and heavy rain $\left(>1 \mathrm{~mm} \mathrm{hr}^{-1}\right)$. The PDF shows a slight shift towards heavy rain about one hour after the peak. Over oceans (Fig. 3b), the PDF shows primary contribution by moderate rain, with a slight shift towards heavier rain during the peak at 4-6 LST, but otherwise remain unchanged throughout the day. The same analy- 
sis was carried out for different monsoon regions, and the aforementioned characteristics were found to be robust and invariant over different large scale monsoon domains. The NSIPP model behavior is quite different compared to observations. Over land (Fig. 3c), the diurnal cycle is mainly due to heavy rain which shows a build-up phase starting in the late morning, following directly the increase in solar heating, and reaching the peak at 13-14 LST. Over the ocean, the model diurnal cycle is due most to light rain $\left(<0.2 \mathrm{~mm} \mathrm{hr}^{-1}\right)$, suggesting an over-abundance of light rain or drizzles in the model.

In the real world, convection over land is initiated by the destabilization of the boundary layer caused by the daytime insolation which peaks at local noon. However the peak rainfall comes in the late afternoon because the induced convective system takes several hours to mature and produce heavy precipitation. The time taken for the rain system to mature is indicated by the overall increase in all rain categories and the shift towards heavier rain during 13-18 LST (Fig. 3a). The early morning maximum of oceanic rainfall has been attributed to a number of factors associated with cloud-radiation-dynamics interaction of the developing cloud system with the surrounding area, and with the delayed response of SST to insolation (Gray and Jacobson 1977; Randall et al. 1991; Sui et al. 1997; and Dai 2001).

The lack of a delayed response in convection over both land and ocean exhibited by the NSIPP model is known to be an endemic problem in all AGCMs that employ cumulus parameterization which does not include realistic lifetime history of convective cycles. These AGCM tends to produce deep convection too readily (Dai and Trenberth 2003). The above results also expose another weakness in rain production in AGCM, i.e. excessive drizzles. Since drizzles are associated with warm rains and stratocumulus clouds which occupy large areas of the tropics, this weakness can lead imbalance in the total energy budget, and produce climate drift in long-term model runs.

\section{b. Regional variations}

This subsection shows examples of regional variations in diurnal cycle in different monsoon regions, by evaluating the TRMM data and model outputs against CEOP in-situ observations. To reduce sampling errors between point measurements, and area averaged quantities, it is necessary to find CEOP reference sites that have multiple $(>10-20)$ observation stations. At the time of writing, three group of reference sites are found i.e., northern South China Sea (NSCS) with 25 stations, the staging area of the Africa Monsoon Multiscale Analyses (AMMA) field experiment with 51 stations, and the Southern Great Plains (SGP) with 23 stations. The former two sites are considered representative of the East Asian monsoon and the West Africa monsoon respectively. The SGP site is strictly speaking not a monsoon domain, but can be considered within the influence zone of the North America/Mexican monsoon. Figure 4 shows the phase of the rainfall diurnal cycle in terms of percentage of daily rain. In the NSCS region, TRMM data shows the influence of land diurnal cycle with maximum rain around 15-17 LST, and a secondary maximum at 2-4 LST, reflecting some oceanic influence, with a clear minimum at approximately 8 LST. The semi-diurnal distribution is also pronounced in CEOP data, but both maxima occur 2-3 hours later compared to TRMM. Relative to CEOP, TRMM underestimates the rain amount in 6-10 LST, and overestimates at 14-18 LST. The reason for this discrepancy is unknown, but may have to do with the different sampling between satellite and gauge network estimates. Noting that the rain at 6-10 LST consists mostly of light rain, and that at 14$18 \mathrm{LST}$ are due to heavy (convective) rain (see Fig. 3), the discrepancy may reflect bias in the TRMM TMI rainfall retrieval algorithm for light (warm) rain, and heavy (cold) rain over land (Nesbitt and Zipser 2002). The NSIPP model shows a weak diurnal cycle with a broad maximum at around noon, and no indication of the bimodal distribution of rainfall. This is likely due to a lack of representation of local topographical influence, coarse model resolution, and inadequate boundary layer and warm rain physics in the model. Over the AMMA region, TRMM and CEOP data both show a pronounced semi-diurnal component with the primary peak at 17-19 LST, and the secondary peak at 4-6 LST. The NSIPP model mimic the semi-diurnal cycle reasonably well, suggesting this signal is likely to be driven by dynamics. 
(a) NSCS

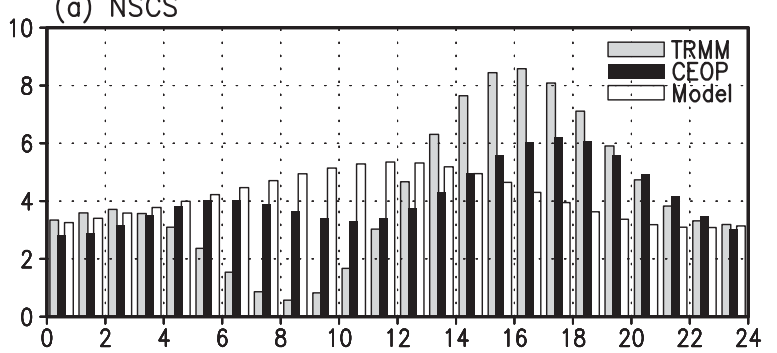

(b) AMMA
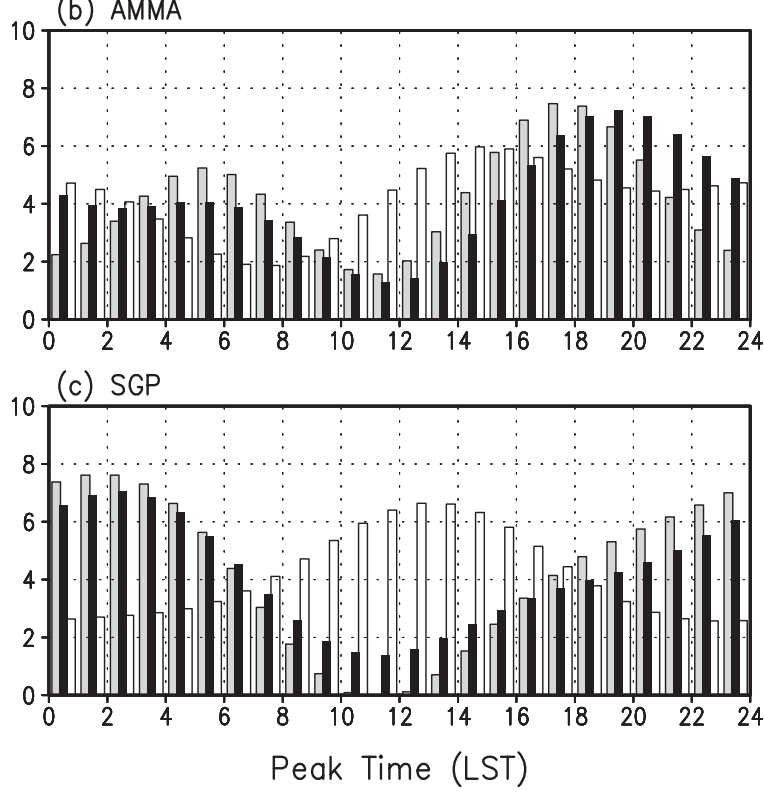

Fig. 4. Composite diurnal cycle in percentage of accumulated hourly rain to total daily rainfall from CEOP data for (a) northern South China Sea, (b) AMMA region, and (c) SGP region, from TRMM (light shaded), CEOP (dark shaded), and NSIPP model (not shaded).

Over the SGP, both TRMM and CEOP capture a nocturnal maximum in rainfall, which is related to the mountain effect (Carbone et al. 2002) and the fluctuation of the low level jet (Helfand and Schubert 1995). The NSIPP model fails to reproduce the nocturnal rainfall maximum, probably due to the insensitivity of model's convection to moisture convergence initiated by mountain effect and low level jet (Lee et al. 2007).

\section{The seasonal cycles}

The monsoon seasonal cycles possess a variety of spatial and temporal scales, which can be broadly separated into a slow and a fast component (Lau et al. 1988; Wang and Xu 1997; Kang et al. 1999). The slow component refers to that part of system that is in quasiequilibrium, and evolves in concert, with the seasonal march of the solar radiation. The fast annual component exists as a result of the phase-locking of dynamically driven intraseasonal oscillation (ISO) with the slow cycle, and can only be seen in daily or pentad means. In this section, we focus our discussion on the seasonal migration of the monsoon rainbelt based on pentad-mean climatology from observations and model for all the six major monsoon systems, i.e., EAM, IM, AUM, WAM, NAMS and SAMS.

\section{a. Basic features}

Figure 5a (upper panel) shows the latitudetime sections of climatological pentad rainfall from TRMM data and from NSIPP GCM (lower panel) for EAM. Clearly seen in Fig. 5a is an abrupt northward propagation of first ISO of the summer season from $10^{\circ} \mathrm{N}$ to $35^{\circ} \mathrm{N}$, signaling the onsets of the EAM, starting in midMay over the South China Sea, to the Mei-yu in June $\left[25-30^{\circ} \mathrm{N}\right]$, and the Baiu or Changmai $\left[35-40^{\circ} \mathrm{N}\right]$ in July. A distinct break is found immediately after the first major climatological ISO (CISO) pulse, and then followed by less regular ISO along latitude belt $10-25^{\circ} \mathrm{N}$. A weaker second pulse of CISO reaching north of $25^{\circ} \mathrm{N}$ can be detected in August. The withdrawal phase occurs rather slowly compared with the onset phase. In addition, there is a rather well-defined pre-monsoon rainy phase in southern China $\left[25-30^{\circ} \mathrm{N}\right]$ in April-May. The model (lower panel) captures the broad features of slow component of the annual cycle, but is less successful in simulating the fast components. Excess rainfall, from 50-100\% more compared to TRMM, is found over the tropical western Pacific $\left[10-20^{\circ} \mathrm{N}\right]$, from JuneOctober (Fig. 1b).

For IM (Fig. 5b, upper panel), the first northward propagation of CISO occurs in May, and then in June. The first is associated with the bifurcation of convection in the Bay of Bengal preceding the onset of the South China Sea monsoon (Lau et al. 1998), and the second is associated with the onset of the Indian monsoon over the west coast of India. Unlike the EAM, 
(a) EAM

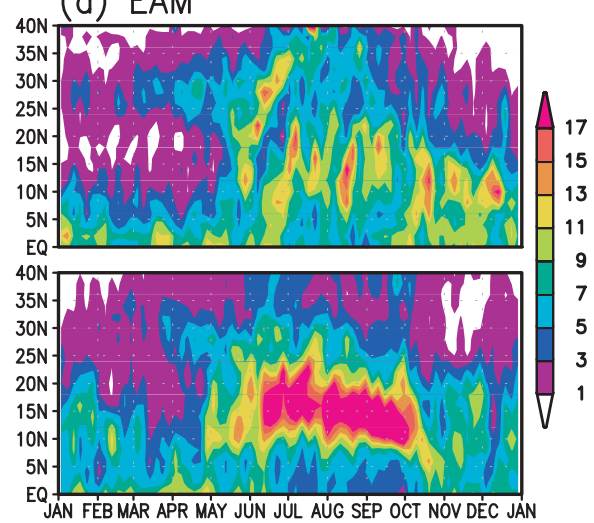

(c) WAM

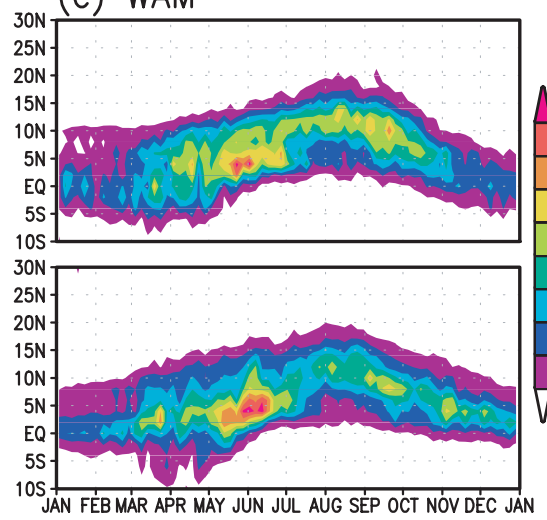

(e) SAMS

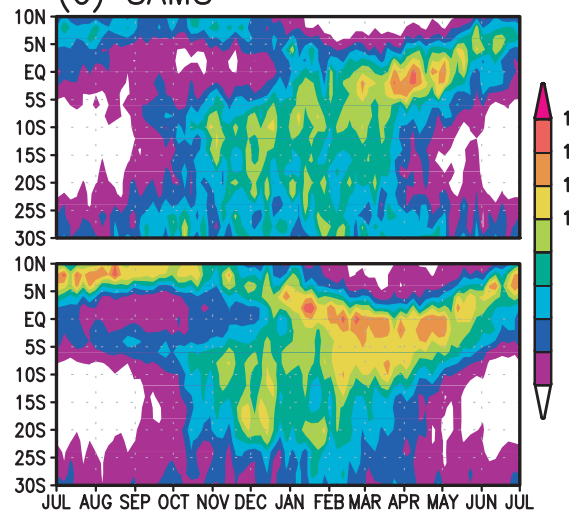

(b) $\mid M$

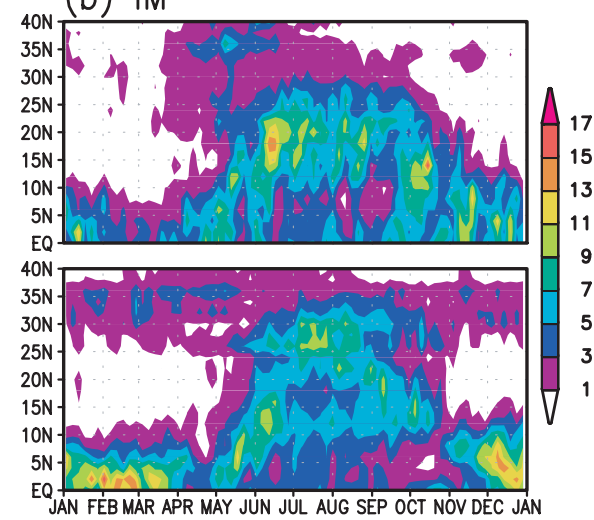

(d) NAMS

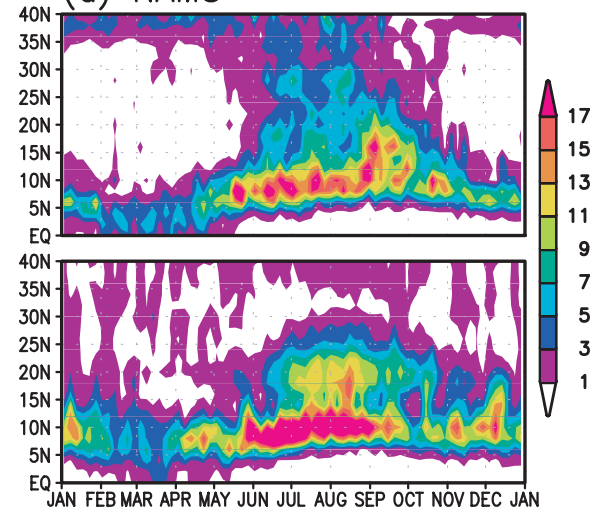

(f) $A \cup M$

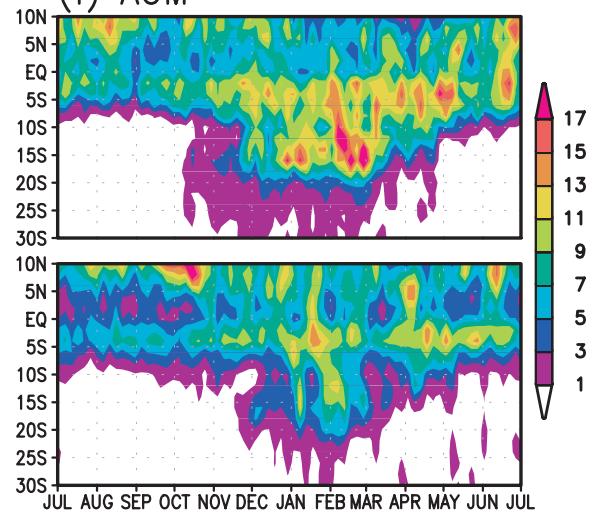

Fig. 5. Time-latitude cross-sections of pentad rainfall data for (a) EAM [110-130 E], (b) IM [70$90^{\circ} \mathrm{E}$ ]: (c) WAM $\left[10^{\circ} \mathrm{W}-10^{\circ} \mathrm{E}\right]$, (d) NAM [120-100 W], (e) SAMS [60-40 $\mathrm{W}$ ], and (d): AUM [125$145^{\circ} \mathrm{W}$ ]. TRMM observations and NSIPP GCM results are shown in upper and lower panels respectively. Units are in $\mathrm{mm}_{\mathrm{day}}{ }^{-1}$.

which has large latitudinal span, the monsoon rain are limited to $25^{\circ} \mathrm{N}$ at the foothills of the Himalayas. Here, the CISO northward propagation signals are detectable, but not as well- defined as EAM. The NSIPP model (Fig. 5b, lower panel) seems to do a reasonably good job in simulating the IM evolution, except in underestimating rainfall over land $\left(15-25^{\circ} \mathrm{N}\right)$, 
and overestimating rainfall north of $25^{\circ} \mathrm{N}$ in the southern Tibetan Plateau. The model rainfall also lacks in the definition of CISO. Excessive rainfall is also found in the equatorial ITCZ in the December through April.

The other two northern hemisphere monsoon systems, i.e., WAM and NAMS have very different climatological seasonal cycle compared to EAM and IM. For WAM (Fig. 5c, upper panel), the monsoon rain belt in June-AugustSeptember appears at the tip of a bow-shaped ITCZ structure, which can be identified with the northward migration of the rain belt from the Gulf of Guinea to the land region of the West Africa immediately to the north. While there is an indication of an abrupt shift from oceanic to land convection in early July, there is no clear signals of monsoon breaks or CISO. The NSIPP model (lower panel) simulates reasonably well the main features of the WAM, but the intensity of the monsoon rain over land is underestimated.

For NAMS, the dominant feature is the ITCZ variation associated with the Mexico monsoon system, which migrates northward to 10$15^{\circ} \mathrm{N}$ during June-July-August (Fig. 5d, upper panel). The North American portion of the monsoon $\left(25-30^{\circ} \mathrm{N}\right)$ is relatively weak, lacking sharp onset or break features as shown by 3-5 mm day ${ }^{-1}$ contour during July-AugustSeptember. A 10-50 day ISO seems to be quite prominent along the axis of the ITCZ with a clear northward jump in late August to early September, but otherwise ill-defined northward propagation. The NSIPP simulates reasonably well the slow component of the ITCZ seasonal cycle of NAMS (Fig. 5d, lower panel). However, the model seems to overestimate the northward expansion of the Mexican monsoon, producing a spurious rain zone at $20^{\circ} \mathrm{N}$, in July-August. The ISO signal is not well simulated either.

Next, we turn to the two southern hemisphere monsoon systems. Figure 5e (upper panel) shows that SAMS is characterized by two major convective systems, one over land and one over the ocean. The land-driven component becomes active in November near 10$15^{\circ} \mathrm{S}$, and splits into a northward and a southward propagating branch. The southern branch penetrates the extratropics up to the La Plata Basin $\left(25-30^{\circ} \mathrm{S}\right)$. The northern branch merges with the Atlantic ITCZ and rainfall over north- eastern Brazil in March-April, and exhibit CISO signals which are somewhat intermittent compared to EAM and IM. The SAMS does not show very well defined monsoon break, although lulls in monsoon rainfall can be detected over the land branch during NDJ. The NSIPP model (lower panel) seems to capture the major features reasonably well. The ITCZ portion of the SAMS appears to be more connected to the oceanic component throughout the year, but less so to the land convection as the observed.

Similar to the SASM, the AUM (Fig. 5f, upper panel) shows strong control by an ITCZ anchored to the maritime continent of Indonesia and Papua New Guinea, and a land-driven rain system over northern Australia in DJF. Two preferred latitudinal zones for active convection is obvious. The first one is clearly related to the ITCZ, which is strongly influenced by the topography of the maritime continent, as evident in the line of active convection at $5^{\circ} \mathrm{S}$ from November through May. The second can be identified with the AUM monsoon convection over northern Australia (15-20 $\left.{ }^{\circ} \mathrm{S}\right)$. Southward propagating CISO's from the ITCZ to northern Australia (south of $10^{\circ} \mathrm{S}$ ) is clearly visible in DJF. The model (lower panel) simulates the land-locked ITCZ rainfall quite well, and to a lesser degree the southward propagating ISOs, but underestimates the monsoon rainfall over northern Australia.

\section{b. Monsoon continentality}

The above analyses show that common to all the monsoon systems is the presence of oceanicdriven intertropical convergence zone (ITCZ)type convection in the deep tropics $\left(10-10^{\circ} \mathrm{N}\right)$, and convective systems outside the ITCZ zone. The latter includes subtropical and extratropical atmospheric and land, as well as oceanic influences outside the tropics, stemming from the presence of continental land mass (CLM) outside the deep tropics. The monsoon characteristics appear to be dependent on the degree by which the system is controlled by the ITCZ vs. the CLM processes. While the former tends to confine the system within the deep tropics, as in the case of a pure oceanic ITCZ, with no land regions to the north and south, the latter tends to draw the monsoon system away from the tropics towards continental land mass. 
To quantify the relative strengths of these two controls, we define the ITCZ convection as the seasonal mean rainfall between the zone from equator to $10^{\circ}$ north or south, and the CLM as that between $10-35^{\circ} \mathrm{N}$ or $\mathrm{S}$, on the same hemisphere as the monsoon system in question. The 10 degree also represents the poleward limit of "pure ITCZ system" as represented by aqua-planet model simulations (Tomita et al. 2005). Figure 6 shows a scattered plot for all six monsoon systems as a function of the ITCZ and CLM strength. For comparison, data points for two pure ITCZ systems (with no land regions to the north and south) over the central Pacific $\left(\mathrm{CP}, 180-160^{\circ} \mathrm{W}\right)$ and the central Atlantic $\left(\mathrm{CA}, 40-60^{\circ} \mathrm{W}\right)$ are also plotted. The monsoon season is June-July-August for EAM

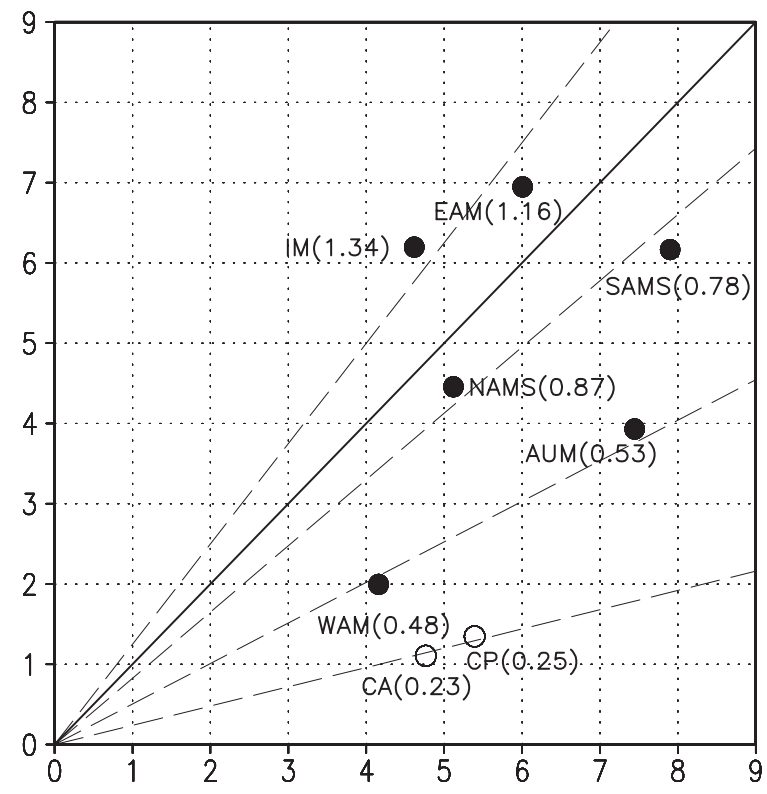

Fig. 6. Scatter plot showing the strength rainfall intensity associated with ITCZtype control on the abscissa and continental control on the ordinate (see text for definition), of all six major monsoon systems (solid circles). For comparison, the data points for the same-size domains over the central Pacific (CP) and the central Atlantic (CA) are also shown (open circles). Units are in $\mathrm{mm} \mathrm{day}^{-1}$. The continentality index $(\Omega)$ is shown in parenthesis. Dashed lines indicate grouping of monsoon systems by $\Omega$. and IM; July-August-September for WAM and NAMS, and December-January-February for SAMS and AUM. In addition, we define a continentality index $(\Omega)$, as the ratio of the CLM to the ITCZ rainfall, which is shown as number inside the parenthesis in Fig. 6. Note that in the theoretical limit of a pure ITCZ system, $\Omega$ is identically equal to zero. If one were to associate the monsoon with the CLM portion only, the strength of the monsoon will be ranked in the order of EAM, IM, SAMS, NAMS, AUM, and WAM. However, if the ITCZ-control is considered only, SAMS will be the strongest and the AUM ranks as a close second, followed by the EAM, and so on.

More revealing is the grouping with respect to $\Omega$, as indicated by the regression lines. Three distinct groups labeled M1-3 can be identified. The IM and EAM belong to a group (M1) where the monsoon is under strong control from both CLM and ITCZ processes, but with slightly stronger contribution from the former, with $\Omega=1.34$, and 1.16 respectively. This mostly likely has to do with the massive Asian continent situated to the north of both monsoons, drawing the monsoon towards the continent against that of the ocean to the south. Interestingly the American monsoons, i.e., the SAMS and NAMS have similar values of $\Omega=0.78$ and 0.87 respectively, indicating slightly stronger ITCZ compared to CLM control (M2). Here the similarity may related to the relative controls of low level jet produced by north-south oriental steep orography in the Altiplano vs. Atlantic ITCZ for the SAMS, and the Sierra Madra Occidental vs. the eastern Pacific ITCZ for the NAMS. Compared to the others, WAM ( $\Omega=0.48)$ and AUM $(\Omega=0.53)$ have the least continentality (M3). The similarity of the relative control of these two monsoons may be related to the presence of the desert regions poleward of the monsoon region, i.e., the great Sahara desert north of WAM, and the Australian desert south of the AUM. These deserts are overlain by low level anticyclonic flow, with strong large scale subsidence, which tend to inhibit the poleward extension of the monsoon, limiting their continental influence. Yet both monsoons are strongly controlled by oceanic ITCZ with strong sea surface temperature meridional gradient on the equatorward side of the land mass. As can be seen, the WAM is clos- 

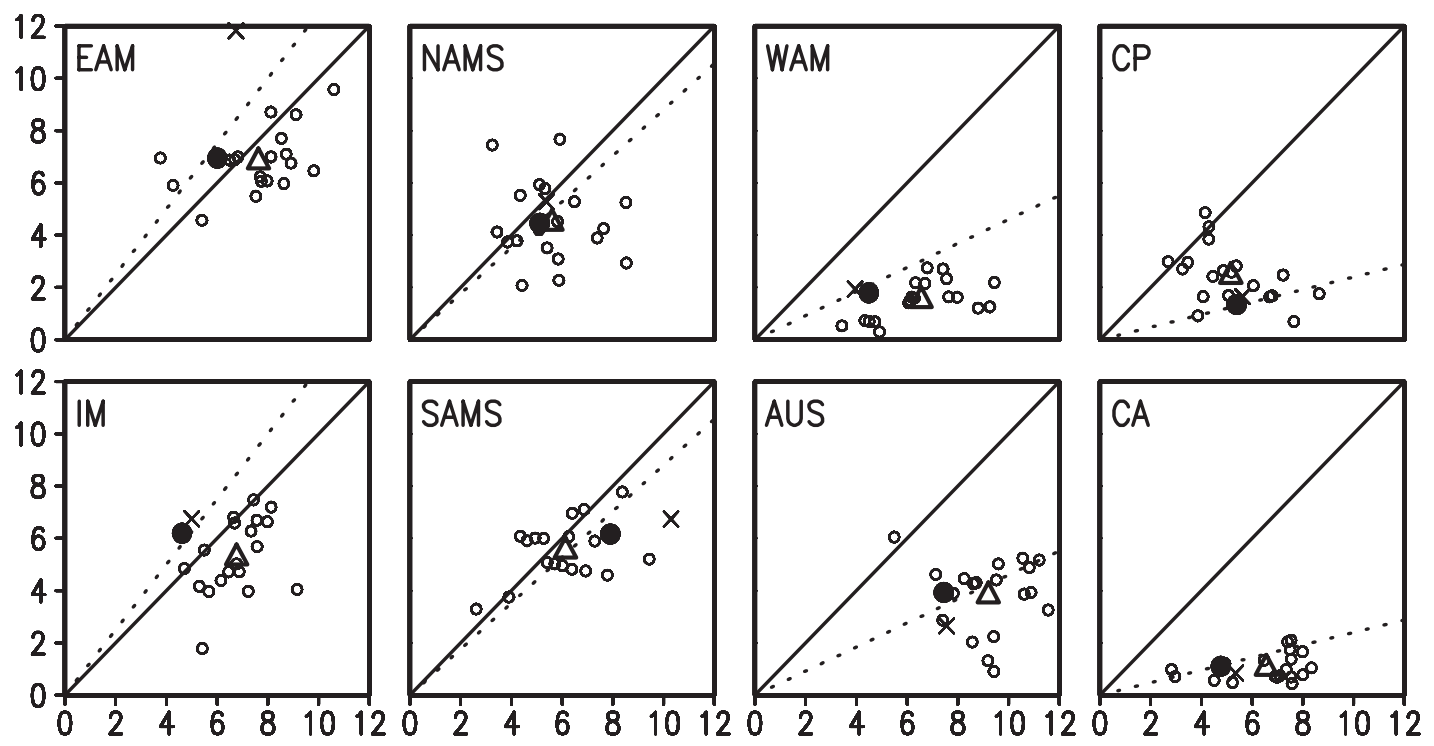

Fig. 7. Same as in Fig. 6, except showing the scattered plots of IPCC coupled models (small open circle), the model ensemble mean (triangle), TRMM observation (large solid circle), and NSIPP model (cross), for each monsoon system separately.

est in continentality to the ITCZ systems of the central Pacific (CP, $\Omega=0.25$ ) and central Atlantic (CA, $\Omega=0.23$ ), suggesting it is primarily an ITCZ monsoon system. We need to point out that a low continental index does not necessarily imply a lack of continental influence on the monsoon, but simply expresses the fact the monsoon convection has a limited meridional span toward continental regions. Xie (2005) has pointed out that the shape of the continent e.g., North America, and Africa, and its location on the eastern side of the ocean basin may be largely responsible for the location of the climatological ITCZ north of the equator, via westward Rossby-wave-induced air-sea interaction.

\section{c. Applications of the continentality index}

In this section, we illustrate the utility of the $\Omega$-index in evaluating model simulations of monsoon, and in identifying possible signals of climate change. Using daily rainfall outputs from the last two decades (1980-2000) from 16 coupled GCMs which participated in the $20^{\text {th }}$ Century simulations for the IPCC, Assessment Report 4 (AR4), we have computed the continentality index for the six monsoon systems, as well as the two intrinsic ITCZ systems, and compared them to the observations. The coupled models are state-of-the-art global climate models with spatial resolution of the order of $2 \times 2.5$ degree, and not higher than $1 \times 1$ degree. Figure 7 shows the scatter plots of IPCC models and observation in terms of the ITCZ and CLM effects on the six monsoon systems. The NSIPP model is included in the plot for reference. For EAM, and IM, while yielding similar value of $\Omega$, the models tends to underestimate the continentality by $10-20 \%$ compared to the observed. The NSIPP model grossly overestimates the continentality compared with the other models. As discussed previously this is due to the excessive oceanic rainfall over the western Pacific, north of $15^{\circ} \mathrm{N}$. On the other hand, NSIPP simulates the IM better than all other models. Models show better consistency for SAMS and less so for NAMS. Modeling the continental component of NAMS requires higher resolution in order to simulate the topographic influence of the regional topography such as the Sierra Madra Occidental, and the Gulf of California. The NSIPP model appears to be an outlier in simulating excessive oceanic ITCZ effect in SAMS, as discussed previously regarding Fig. 5e. Models show reasonably good skills in simulating the ITCZ monsoon systems of WAM and AUM, but as for other monsoons, 


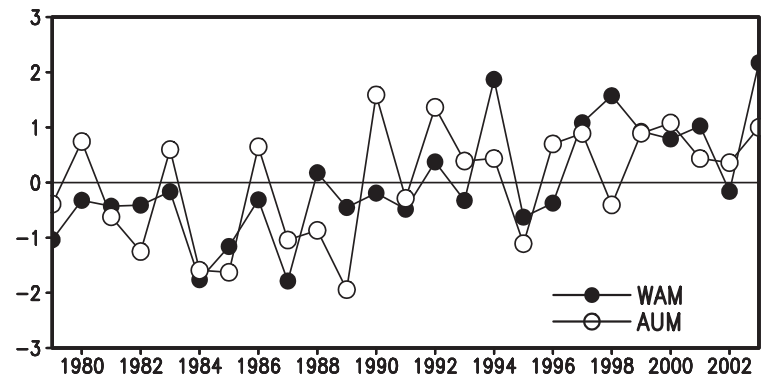

Fig. 8. Time series of continental index anomaly (long-term mean removed) for (a) WAM and (b) AUM from GPCP rainfall data for the period 1980-2003.

have a tendency to underestimate the continental effects. As a whole, the models have more problems with the AUM than WAM, mainly because of the difficulty of simulating the maritime continent convections. The ITCZ systems are reasonably simulated for the central Atlantic, but less so for the central Pacific.

Because the $\Omega$-index is defined as the ratio of CLM to ITCZ convection, it is particularly sensitive to meridional migration of the monsoon rainbelt. As a further example of the utility of the $\Omega$-index in detecting possible long-term meridional shift in monsoon rainbelt, we have computed the yearly $\Omega$-index using GPCP rainfall data for the data record (1979-2003) for all six monsoon systems. We found a significant trend of increasing continentality only for M3 monsoon, i.e., WAM and AUM, but not the other monsoon system (see Fig. 8 for WAM and AUM). The trends for the WAM and AUM are significant at $95 \%$ confidence level based on the $R^{2}$-test (Wilks 1995). This result is also confirmed in the contingency table analysis of occurrence of major events during the first half (1979-1990), and the second half (1991-2003) of the data period (see Table 1). For the WAM, the increased continentality in the second half compared with the first is very clear. All 7 major positive $\Omega$ events (defined as those with normalized standard deviation $>0.75$ ) are found in the second half, with none in the first half, and all 4 major negative events in the first half, but none in the second half. Similarly, for AUM, 5 major positive events occur in the second half, but only 2 in the first half, and 6 major negative events in the first half, and only
Table 1. Table showing the frequency of occurrence of major positive and negative events, as indicted by the fluctuation of the continentality index for six major monsoon system, during the first half (1979-1991) and second half (1992-2004) of the data period.

\begin{tabular}{|c|c|c|c|c|}
\hline & \multicolumn{2}{|c|}{ EAM } & \multicolumn{2}{|c|}{ IM } \\
\hline & $>0.75 \sigma$ & $<-0.75 \sigma$ & $>0.75 \sigma$ & $<-0.75 \sigma$ \\
\hline 1979-1991 & 3 & 5 & 3 & 4 \\
\hline \multirow[t]{2}{*}{$1992-2004$} & 4 & 2 & 3 & 2 \\
\hline & \multicolumn{2}{|c|}{ NAMS } & \multicolumn{2}{|c|}{ SAMS } \\
\hline 1979-1991 & 3 & 3 & 3 & 3 \\
\hline \multirow[t]{2}{*}{$1992-2004$} & 1 & 2 & 1 & 2 \\
\hline & \multicolumn{2}{|c|}{ WAM } & \multicolumn{2}{|c|}{ AUM } \\
\hline 1979-1991 & 0 & 4 & 2 & 6 \\
\hline 1992-2004 & 7 & 0 & 5 & 2 \\
\hline
\end{tabular}

two in the second half. Table 1 also suggests a tendency for positive continentality trend in EAM, with 4 positive events in the second event compared to three negative event in the second half, and 5 negative events in the first half compared to 2 positive events in the second half. The positive trend in continentality in WAM is consistent with the partial recovery of the Sahel drought since the 1980's. Since both WAM and AUM are ITCZ-monsoon types, the increase in continentality implies a poleward shift of the monsoon ITCZ from its climatological position. We do not find significant trend in $\Omega$ for the central Pacific, and central Atlantic ITCZ system, suggesting that the trend is related to monsoon coupled atmosphere-landocean processes.

\section{Conclusions}

We have compared and contrasted climatological diurnal cycles over monsoon land and ocean regions, and seasonal cycles for six major monsoon systems around the world. Over monsoon land regions, the diurnal cycle has a pronounced late afternoon peak in rainfall and over the oceans a much weak diurnal signal with an early morning peak. The NSIPP GCM produces a daily peak in rainfall about 2-3 hours earlier than observed. This appears to be a common problem with models using a cumulus parameterization which does not include 
cloud life cycle effects, and which lacks detailed treatment of boundary layer processes. Results show rainfall seasonal cycles of all monsoon systems are controlled by an ITCZ component, and an off-equatorial component, which is strongly controlled by processes associated with the presence of large continental land mass. Strong CISO's are found in EAM and IM, SAMS and AUM, but less so in WAM and NAMS. The NSIPP model captures the slow component seasonal component reasonably well, but the CISO's are not well simulated. In particular, the NSIPP model overestimates rainfall over the tropical western Pacific for EAM.

With reference to a new monsoon continentality index, we find that the major monsoon can be classified into three major groups. The EAM and IM belong to a group (M1), where the continental influence is stronger than ITCZ influence. The NAMS and SAMS fall into a second group (M2), where the ITCZ influence is slight stronger than continental influence. Finally, WAM and AUM are found to be essentially ITCZ-monsoon systems (M3), with high oceanic influence but relatively limited continental influence. We find that IPCC coupled models tend to underestimate the continentality of all regional monsoons, i.e., too much precipitation associated with ITCZ systems, but less monsoon rainfall in subtropics and extratropics, and therefore exhibits less continentality compared to the observed. The former is related to problems in cumulus and cloud parameterization, and the latter may be related to the inadequacy in land-atmosphere interaction processes in models.

We show an example illustrated the utility of the $\Omega$-index to detect a possible climate shift associated with an increase in continentality for the ITCZ-type (M3) monsoons of WAM and the AUM in the last two decades. The former is consistent with the recovery of the Sahel drought since the 1980's. The Sahel drought in the 1950-1970's has been attributed to concomitant SST warming of the tropical Atlantic and the Indian Ocean, which strengthens the oceanic ITCZ, and enhances subsidence over the Sahel region (Zeng 2003; Lau et al. 2006). Yet, the increase in continentality, implies a poleward migration of the ITCZ despite the near equatorial sea surface temperature in the At- lantic has been increasing in the last 20 years (Lau and Weng 1999). In ongoing GCM study, the authors have suggested that a positive feedback associated with direct heating due to absorption of solar radiation by increased dust loading in the atmosphere may produce a positive feedback resulting in the intensification and the inland migration of the WAM convection. An intriguing possibility is that this effect may overpower or initiate a turnaround of the increased warming in the Indian Ocean and the equatorial Atlantic, leading to a partial recovery of the Sahel rain. Obviously more work need to be carried out to confirm or refute this speculation.

In closing, clearly there is much to be learned using the CIMS approach in treating individual monsoons as parts of a total system. By intercomparing the diurnal and seasonal cycles among the different monsoons, it is possible to gained new understanding of not only the mechanisms of these natural cycles, but also possible long-term changes in individual and the total monsoon system, and in doing so finding pathways for improving model physic. Further studies using CEOP and ancillary data will be extremely useful to validate the preliminary findings, and expand the scope of this work.

\section{Acknowledgement}

This work is supported by the NASA Precipitation Measurement Mission (PMM), and the NASA Energy and Water Science (NEWS) Program.

\section{References}

Asai, T., S. Ke, and Y.M. Kodama, 1998: Diurnal variability of cloudiness over East Asia and the western Pacific ocean as revealed by GMS during the warm season. J. Meteor. Soc. Japan, 76, 675-684.

Bacmeister, J.T. and M. Suarez, 2002: Wind Stress Simulations and the Equatorial Momentum Budget in an AGCM. J. Atmos. Sci., 59, 30513073.

Carbone, R.E., J.D. Tuttle, D.A. Ahijevych, and S.B. Trier, 2002: Inferences of predictability associated with warm season precipitation episodes. J. Atmos. Sci., 59, 2033-2056.

Dai, A., 2001: Global precipitation and thunderstorm frequencies. Part II: Diurnal variations. J. Climate, 14, 1112-1128. 
Dai, A. and K.E. Trenberth, 2003: The diurnal cycle and its depiction in the community climate system model. J. Climate, 16, 930-951.

Ding, Y.H. and D.R. Sikka, 2006: Synoptic Systems and Weather, The Asian Monsoon, B. Wang, Ed., Praxis Springer, 131-201.

Gray, W.M. and R.W. Jacobson Jr., 1977: Diurnal variation of deep cumulus convection. Mon. Wea. Rev., 105, 1171-1188.

Gu, G. and R.F. Adler, 2004: Seasonal Evolution and Variability Associated with the West African Monsoon System. J. Climate, 17, 3364-3377.

Helfand, H.M. and S.D. Schubert, 1995: Climatology of the simulated Great Plains low-level jet and its contribution to the continental moisture budget of the United States, J. Climate, 8, 784-806.

Higgins, R.W., Y. Yao, and X.L. Wang, 1997: Influence of the North American Monsoon system on US summer precipitation Regime. J. Climate, 10, 2600-2622.

Imaoka, K. and R.W. Spencer, 2000: Diurnal variation of precipitation over the tropica oceans observed by TRMM/TMI combined with SSM/I. J. Climate, 13, 4149-4158.

Janicot, S. and B. Sultan, 2001: Intraseasonal modulation of convection in West Africa Monsoon. Geophys. Res. Lett., 28, 523-526.

Kang, I.-S., C.-H. Ho, Y.-K. Lim, and K.-M. Lau, 1999: Principal Modes of Climatological Seasonal and Intraseasonal Variations of the Asian Summer Monsoon. Mon. Wea. Rev., 127, 322-340.

Lau, K.M. and H. Weng, 1999: Interannual, decadalinterdecadal and global warming signals in sea surface temperature during 1955-97. J. Climate, 12, 1257-1267.

Lau, K.M., G.J. Yang, and S. Shen, 1988: Seasonal and intraseasonal climatology of summer monsoon rainfall over East Asia. Mon. Wea. Rev., 116, 18-37.

Lau, K.M., J. Matsumoto, M. Bolasina, and H. Berbery, 2004: Diurnal variability in the monsoon region: Preliminary results from the CEOP Inter-Monsoon Studies (CIMS). CEOP Newsletter, 5, 2-4.

Lau, K.M., S.S.P. Shen, K.-M. Kim, and H. Wang, 2006: A multi-model study of the twentiethcentury simulations of Sahel drought from the 1970s to 1990s, J. Geophys. Res., 111, D07111, doi:101029/2005JD006281.

Lau, K.-M., H.T. Wu, and S. Yang, 1998: Hydrologic processes associated with the first transition of the Asian summer monsoon: a pilot satellite study. Bull. Am. Meteor. Soc., 79, 1871-1882.

Lee, M.-I., S.D. Schubert, M.J. Suarez, I.M. Held, N.-C. Lau, J.J. Ploshay, A. Kumar, H.-K. Kim, and J.-K.E. Schemm, 2007: An analysis of the warm season diurnal cycle over the continental United States and northern Mexico in general circulation models. Submitted to J. Hydrometeor., in press.

Leese, J., 2001: Coordinated Enhanced Observing Period (CEOP) Implementation Plan. International GEWEX Project Office, Publication Series No. 36e.

Manton, M.J. and J.L. McBride, 1992: Recent research on the Australian monsoon. J. Meteor. Soc. Japan, 70, 275-285.

Marengo, J.A., B. Liebmann, V. Kousky, N. Filizola, and I.C. Wainer, 2001: onst and end of the rainy season in the Brazilian Amazon Basin. J. Climate, 14, 833-852.

Matsumoto, J. and H. Takahara, 2005: Intercomparisons of seasonal changes between East Asian and South American monsoons. CEOP Newsletter, 7, 5-7.

Meisner, B.N. and P.A. Arkin, 1987: Spatial and annual variations in the diurnal cycle of largescale tropical convective cloudiness and precipitation. Mon. Wea. Rev., 115, 2009-2032.

Moorthi S. and M.J. Suarez, 1992: Relaxed Arakawa, Schubert: A parameterization of moist convection for general circulation models. Mon. Wea. Rev. 120, 978-1002.

Negri, A., T.L. Bell, and L. Xu, 2002: Sampling of the diurnal cycle of precipitation using TRMM. J. Atmos. and Oceanic Tech., 19, 1333-1344.

Nesbitt, S.W. and E.J. Zipser, 2002: The diurnal cycle of rainfall and convective intensity according to three years of TRMM measurements. J. Climate, 16, 1456-1475.

Randall, D.A., Harshvardhan, and D.A. Dazlich, 1991: Diurnal variability of the hydrologic cycle in a general circulation model. J. Atmos. Sci., 48, 40-62.

Roads, J., M. Bosilovitch, M. Kanamitsu, and M. Rodell, 2003: Scientific report on WESP CEOP Pilot Data Comparisons. CEOP Newsletter, 3, 2-5.

Sorooshian, S., X. Gao, K. Hsu, R.A. Madox, Y. Hong, H. Gupta, and H.B. Imam, 2002: Diurnal variability of tropical rainfall retrieved from combined GOES and TRMM satellite information. J. Climate, 15, 983-1001.

Suarez M.J. and L.L. Takacs, 1995. Documentation of the Aries/GEOS dynamical core version 2. NASA Tech. Memo. 104606, Vol. 10, 56 pp.

Sui, C.H., K.M. Lau, Y.N. Takayabu, and D.A. Short, 1997: Diurnal variations in tropical oceanic cumulus convection during TOGA COARE. $J$. Atmos. Sci., 54, 639-655.

Tomita, H., H. Miura, S. Iga, T. Nasuno, and M. 
Satoh, 2005: A global cloud resolving model simulation: Preliminary results from an aquaplanet experiment. Geophys. Res. Lett., 32, L08805, doi:10.1029/2005GL022459.

Wang, B. and X. Xu, 1996: Northern Hemisphere Summer Monsoon Singularities and Climatological Intraseasonal Oscillation, Journal of Climate, Vol. 10, No. 5, pp. 1071-1085.

Wilks, D.S., 1995: Statistical methods in the atmospheric sciences. Academic press, $467 \mathrm{pp}$.

Xie, S.-P., 2005: The shape of continent, air-sea in- teraction, and the rising branch of the Hadley Circulation. The Hadley Circulation: Present, Past and Future, H.F. Diaz and R.S. Bradley, Eds, Springer, 173-202.

Yang, D.P. and J. Slingo, 2001: The diurnal cycle in the tropics. Mon. Wea. Rev., 129, 784-801.

Zeng, N., 2003: Droughts in the Sahel. Science, 301, 999-1000.

Zhou, J. and K.M. Lau, 1998: Does a monsoon climate exist over South America. J. Climate, 11, 1020-1040. 